\title{
The use of substations with PCM heat accumulators in district heating system
}

\author{
Kinga Nogaj ${ }^{*}$, Michat Turski, and Robert Sekret \\ Faculty of Infrastructure and Environment, Czestochowa University of Technology, 60A Brzeznicka \\ St., 42-200 Czestochowa, Poland
}

\begin{abstract}
The main objective of the article is to indicate the directions of development of new generations of supplying buildings with heat, by using phase change materials, referring to the technical possibilities of applying available heat storage technologies. As a detailed objective of the work, the determination of the impact of using a PCM accumulator on the temperature of the heat carrier on the return in the substation of the district heating system was adopted. Range work included determination of parameters of heat distribution network as a function of outdoor air temperature range of $-20^{\circ} \mathrm{C}$ to $+12^{\circ} \mathrm{C}$. As the analysis object, the heat substation has been selected with the following parameters: supply $80^{\circ} \mathrm{C}$ and return $60^{\circ} \mathrm{C}$. It was found that thanks to the use of PCM accumulators on heat substations, it is possible to save energy by up to approx. $6.7 \%$ and achieve economic benefits in the form of a payback period of approx. 13 years. In addition, it was found that the introduction of the PCM accumulator into the heating system allows the return temperature in the heating network to be obtained at a temperature level consistent with the adopted control table for external temperatures of the standard heating season.
\end{abstract}

\section{Introduction}

Energy saving is realized through thermal modernization of buildings. Any changes in the structure of the heating system, ie. the use of renewable energy sources (RES), use of waste heat and thermo-modernization lead to the emergence of new thermal and flow conditions in the heating network, which on the one hand lead to a reduction in the heat load of buildings (reduction of non-renewable primary energy carriers in buildings) up to the other side of disruption of the heating network operation and its transmission and adjustment efficiency [1].

The heat is delivered to users based on the adopted regulation curve. Due to carried out thermo-modernization of buildings or the introduction of renewable energy, users consume much less heat, which causes an increase in return temperature in the heating network. The difference between the temperature of the return of the network under real conditions and under the design conditions is treated as a loss for the heating system [2]. If the return temperature of the network reaches higher values than the design temperature (appropriate

* Corresponding author: k.nogaj@is.pcz.pl 
for the efficient operation of the entire system), there is a need to cool down the return water to the temperature level determined for the expected work of the heat source, ie the heating plant or the combined heat and power plant (CHP). This procedure generates losses [3]. On the one hand, these are heat losses (dissipation of heat to the environment), on the other hand, the efficiency of the heating system decreases (increase in the cost of maintaining the CHP).

It follows that rational energy management in the heating system should reduce the amount of heat dissipated as much as possible. One of the proposed ways to reduce the amount of heat dissipated can be a heat storage. Therefore, a very important element in the development of heating networks is to conduct research on heat storage in a distributed system using phase change heat [4].

It is assumed that in the new generation of heating networks, the main task of heat sources will be the exchange of energy with external network systems, and not only covering the energy needs of the building [5]. Heat substations present in the heating network may perform such a function.

\section{Theory}

The substation is currently an important element of the heating network, where savings are sought by increasing the efficiency of transferring the heat generated to the end user [6]. A typical task of a heat substation is to transfer heat from a medium that circulates in the network to water in receiving installations of a building.

The integration of new elements with the heating network, such as PCM accumulators and renewable energy sources, makes it necessary to create a basis for technical and technological functioning of the newer generation of district heating networks. Such bases may be hybrid nodes connecting the heat gaining heat from renewable sources, waste heat recovery and heat storage primarily using new technologies [6-8].

Heat storage due to the fact that the cheapest energy is waste energy used as useful energy or saved is a particularly interesting aspect [9]. Therefore, this work focuses on the aspect of heat storage in the heating system. It is estimated that in domestic heating systems, where heat production amounted to $421.3 \mathrm{PJ}$ and $\mathrm{CO}_{2}$ emission amounted to 43 million tons per year, the theoretical potential of waste heat possible to be stored is 53.5 PJ, which currently creates the potential for financial savings at PLN 2.4 billion a year [10,11].

The observed effect of increasing heat losses in the district heating system is the reduction of its total efficiency, and thus also the economic efficiency. The overall efficiency of the heating system $\left(\eta_{c}\right)$ consists of: heat generation efficiency $\left(\eta_{\mathrm{w}}\right)$, heat storage efficiency $\left(\eta_{\mathrm{a}}\right)$, heat distribution efficiency $\left(\eta_{\mathrm{d}}\right)$ and heat regulation and utilization efficiency $\left(\eta_{\mathrm{r}}\right)$, which determines the dependence 1 :

$$
\eta_{\sigma}=\eta_{w} \cdot \eta_{\sigma} \cdot \eta_{\text {d }} \cdot \eta_{r}
$$

In the literature of the subject of research, there are proposals for new technologies to increase the efficiency of the system, but these are mainly solutions within one efficiency, for example attempts to connect solar collectors to the grid $[14,15]$ cogeneration $[12,13]$ trigeneration [14] use pre-insulated wires [15,16] or the use of heat pumps [17]. At the moment, there are no comprehensive technological solutions that improve the overall efficiency of the entire system.

Therefore, the storage of heat is a particularly interesting element of improving the efficiency of the heating system operation. Currently, water storage solutions located at the source [18] are used for the heat storage process. Their task is to reduce the peak power of the source. However, the use of a dispersed heat accumulator is able to ensure the 
improvement of the efficiency of the entire heating system [19]. PCM accumulator located in substation was used in the work.

Phase-change materials (PCM) in the industrial heating are not common. This situation is caused by insufficient knowledge in the use of heat accumulation technology using phase change [13]. Solutions with the use of phase change materials are most often present in the simulation or research phase $[1,12]$.

PCM materials are a promising solution, due to: the large thermal capacity in relation to the mass and volume, the significant potential for heat recovery at a relatively constant temperature of the medium and the ability to store large amounts of heat.

Based on the conducted literature review, it is stated that in the polish and global heating systems there is an increased use of waste heat and the introduction of renewable energy sources [2,9]. Modernization of existing heat substations in terms of solutions integrating several types of useful forms of energy has not been presented in any available scientific work, and as is clear from the subject of this paper, the development of the heating network through streamlining heat substations seems to be particularly interesting. Therefore, it was undertaken to carry out of the substations tests using a PCM accumulator.

\section{Study object}

For the analysis of the possibility of connecting the PCM accumulator district heating, district heating has been identified as a representative network of heating occurs in an urban area. It was assumed that the network supplies heat to approx. 240 thousand. Inhabitants and covers an area of $160 \mathrm{~km}^{2}$. The total length of the district heating network is $170 \mathrm{~km}$. The parameters of heating grid as a function of outdoor air temperature ranged from $-20^{\circ} \mathrm{C}$ to $12^{\circ} \mathrm{C}$. Adjusting the source is performed using the regulatory table.

The heat station adopted for the analysis was located in the third climate zone. The regulation range of the installation's work was within the temperature range of $-20^{\circ} \mathrm{C}$ and $12^{\circ} \mathrm{C}$. The characteristics of the analyzed heating substation were: $80^{\circ} \mathrm{C}$ supply, $60^{\circ} \mathrm{C}$ return for extremely low outside air temperatures, heat demand for c.o. was Qc.o. $=280 \mathrm{~kW}$ and the mass flow $\mathrm{m}=5.136 \mathrm{~kg} / \mathrm{s}$. The customer's substation is provided with a qualitative heat supply regulation.

\section{Methodology}

The analysis included determination of the impact of PCM accumulator connection on the substation of the analyzed installation and determination of the energy and economic effect of the proposed solution. The methodology referred to two configurations of the heating system depending on the type of heat storage used: lack of storage and storage in a distributed system. Configurations of heating systems are shown in Figures 1, 2.

The first configuration, hereinafter referred to as reference conditions, is a standard solution for the heating system. 


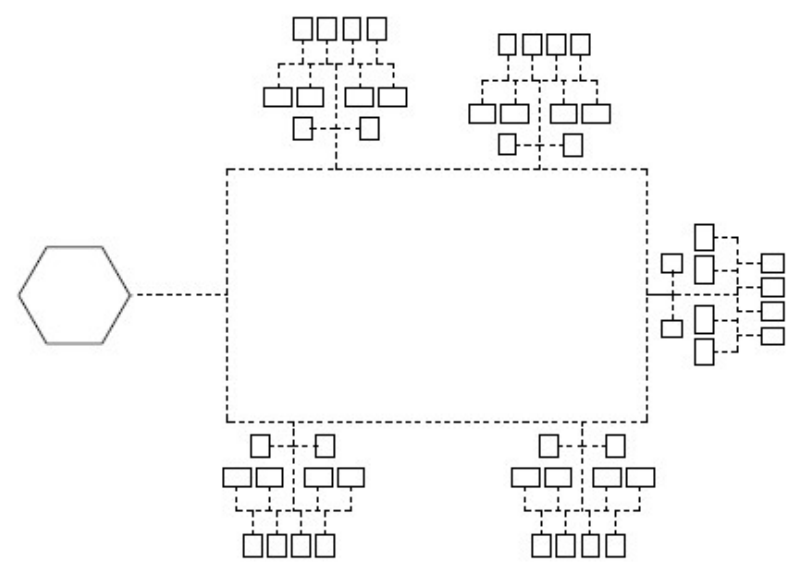

Fig. 1. Reference conditions. Standard heating system (without storage).

The second configuration, hereinafter referred to as variant 1 , is the use of distributed PCM heat accumulators on each heat distribution node. The conducted analysis concerns one selected substation.

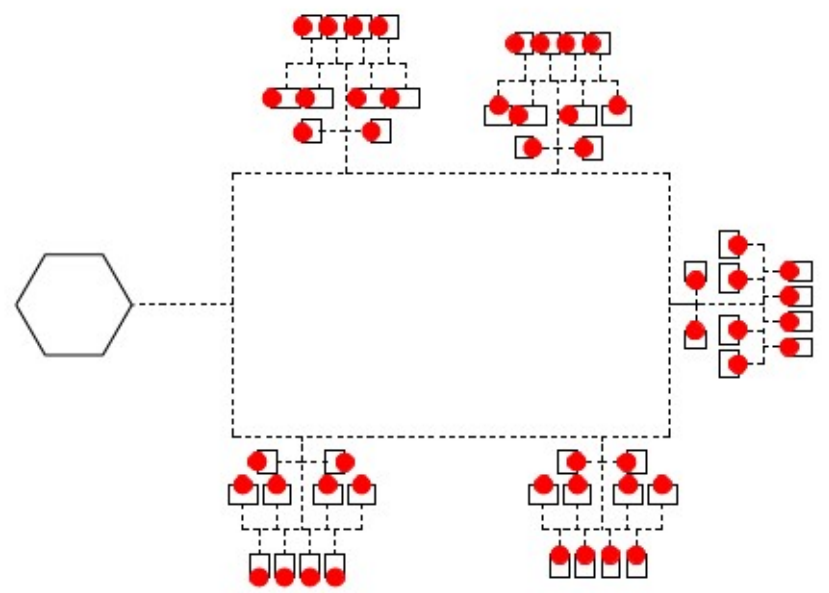

Fig. 2. Variant 1. District heating network using PCM accumulators.

The research methodology has been divided into two stages: defining the operating parameters and determining the effects of the proposed solution.

The first stage research methodology was to determine the amount of heat that can be stored in the analyzed substation using equation (2), PCM accumulator volume selection, using equation (3) and determining the return water temperature difference using a PCM accumulator on the substation using the equation (4).

$$
\begin{aligned}
& \dot{Q}=\dot{m} \cdot c_{p} \cdot \Delta \mathrm{T}, \mathrm{W} \\
& V_{\text {st }}=\frac{m_{\text {st }}}{\rho_{\text {av }}} \cdot 10^{-3}, \mathrm{~m}^{3}
\end{aligned}
$$




$$
t p_{a k u}=-\frac{\Delta Q_{s t}}{\dot{m} \cdot c_{p}}+t p_{r z}
$$

The second stage research methodology consisted in determining the energy and economic effect of the proposed solution. The energy effect, expressed in equation 5 , is understood as the potential to reduce final energy consumption due to a part of the accumulated energy (consumption of fossil fuels needed to produce usable and heat energy). It also results from maintaining the return temperature of the network at the design temperature level, consistent with the regulatory table. The economic effect, expressed in equation 6 , results from the savings in fuel consumption and the reduction of heat loss during transmission.

$$
\begin{aligned}
& \Delta Q_{W n}=Q_{W o}-Q_{W o+1}, \frac{G J}{a} \\
& E_{\text {conE }}=\Delta Q_{W n} \cdot P_{G J}, \frac{£}{a}
\end{aligned}
$$

The equations for regulating the temperature distribution of the network water discussed in the paper [17] were used for the calculation.

\section{Results}

Following the adopted methodology, the amount of heat available for storage in the analyzed substation, which amounted to approximately $850 \mathrm{GJ} / \mathrm{a}$, was determined. Individual shares of unreceived heat are presented in figure 3 . In the standard heating season, the largest amounts of heat available for storage (over $140 \mathrm{GJ} / \mathrm{a}$ ) were observed in December, January and February. In the remaining months, the amount of heat was from 19 GJ/a to $137 \mathrm{GJ} / \mathrm{a}$. Taking into account the lack of data for the full months - October and April (the heating season has been analyzed, ie the period from October 10 to April 8), it can be stated that the highest amounts of heat occur in the peak heating season (December $160 \mathrm{GJ} / \mathrm{a}$, January $182 \mathrm{GJ} / \mathrm{a}$, February $157 \mathrm{GJ} / \mathrm{a}$ ), and the smallest in the transition period (March 137 GJ/a, November 121 GJ/a, October 77 GJ/a and April 19 GJ/a).

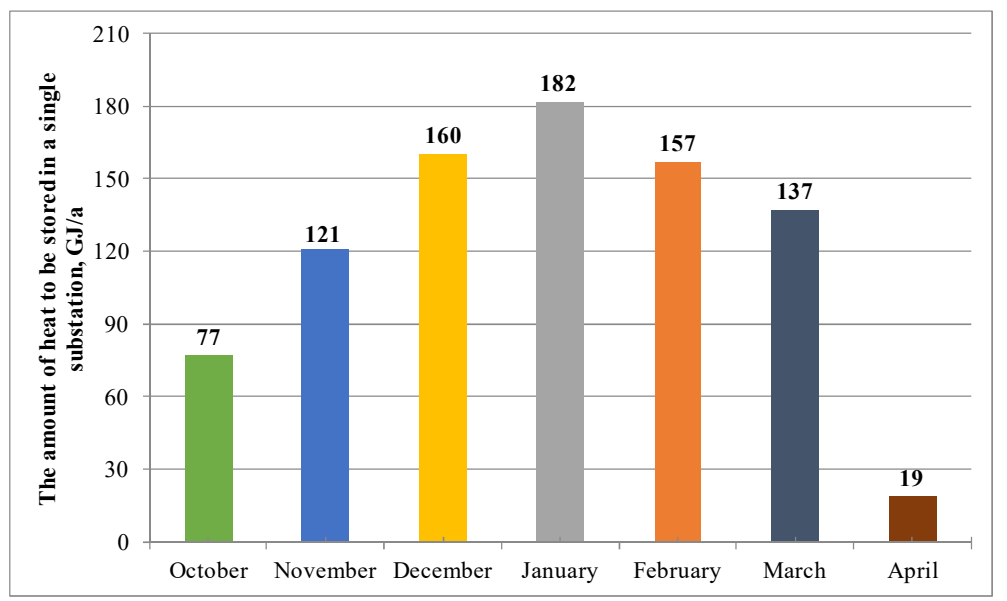

Fig. 3. The amount of heat possible for storage in a single substaion in standard heating system. 
For the analyzed heat distribution node the volume of the PCM accumulator, which was in the range of 22-30 $\mathrm{m}^{3}$, was also estimated. The summary is shown in Figure 4. One of the curves represents the volume of the PCM accumulator and the other shows amount of heat to be stored. The range of PCM accumulator volume selection in the analyzed substation in relation to the outside air temperature was determined, which was marked a straight line. The intersection points of the PCM accumulator volume selection curve with the most frequent outdoor air temperatures of $-2^{\circ} \mathrm{C}$ and $+5^{\circ} \mathrm{C}$ indicate the optimum volume.

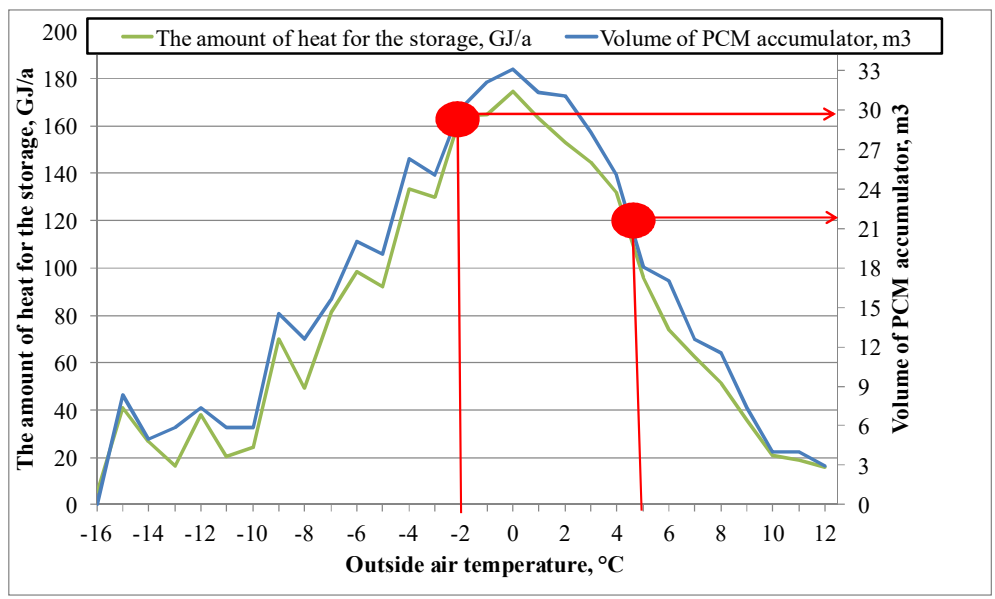

Fig.4. PCM accumulator volume.

Outside air temperature in the standard year reached the range of $-2^{\circ} \mathrm{C}$ to $+5^{\circ} \mathrm{C}$, then the return temperature of the heating network most often occur in the range from $47^{\circ} \mathrm{C}$ to $56^{\circ} \mathrm{C}$. The phase change temperature of the PCM material should be predicted at this temperature, in accordance with previously performed tests described in publications $[13,16]$.

The use of PCM accumulator on substation has allowed to limit the temperature discrepancy of the heating network return, which is presented in Figure 5. The highest curve represents the supply temperature of the heating network in relation to the outside air temperature (the lowest curve). The middle curves represent the return temperature under real conditions, where the highest temperature fluctuations were $30 \mathrm{~K}(\Delta \operatorname{Tmax}=30 \mathrm{~K})$ and the return temperature of the installation using a PCM accumulator, where the highest temperature fluctuations were $10 \mathrm{~K}(\Delta \mathrm{T} \max =10 \mathrm{~K})$. By reducing the temperature difference of the return water in the system with the PCM accumulator, it was possible to improve the network regulation by $67 \%$. 


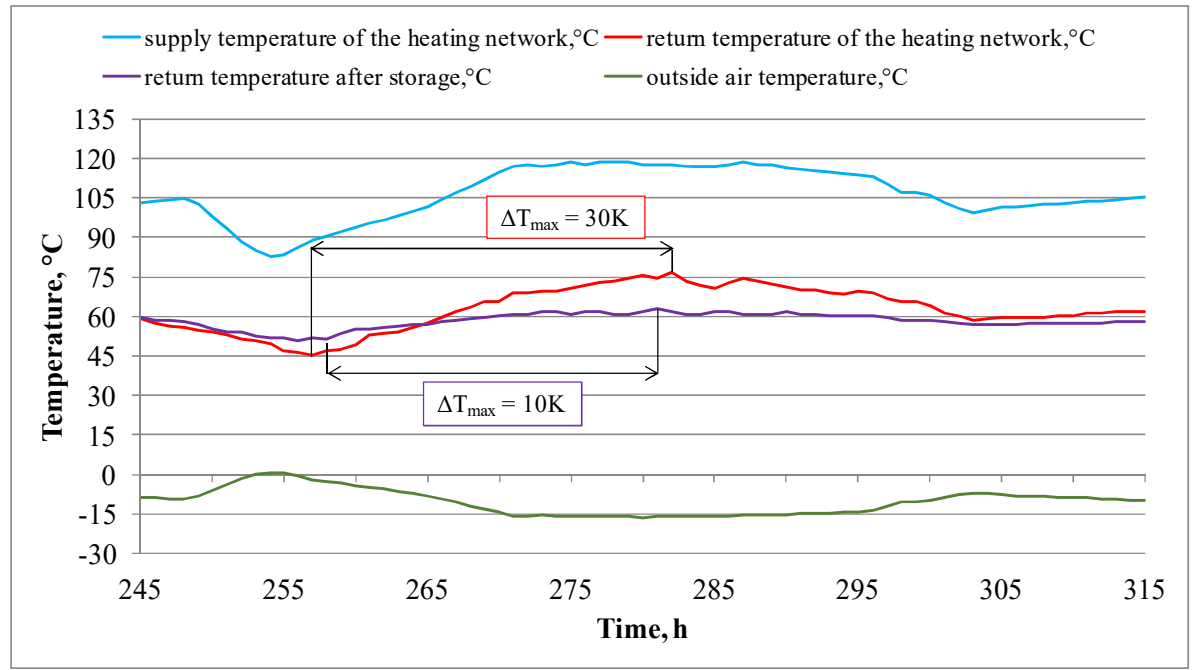

Fig.5. Restriction gap return water temperature in the system with PCM accumulator.

On the basis of the energy analysis performed of the relative effect of the energy dependence on the PCM accumulator volume, dependence is presented in Figure 6. It is stated that the proposed solution is energetically justified. The maximum relative energy effect is in the $3-6.5 \%$ range and results from the heat storage and retention of the return temperature at a relatively constant level. The optimal PCM accumulator volume has been determined in accordance with step 1.

As a result of the conducted energy analysis, it was found that the smaller the slope angle of the linear function graph to the $\mathrm{x}$ axis, the faster the increase of the energy effect. Therefore, it is advisable to reduce the PCM accumulator volume. It is found that the smaller the volume, the more $\Delta \mathrm{E}\left(0.38 \%\right.$ per $\left.\mathrm{m}^{3}\right)$, while the larger the volume of the accumulator reduces $\Delta \mathrm{E}\left(0.32 \%\right.$ per $\left.\mathrm{m}^{3}\right)$.

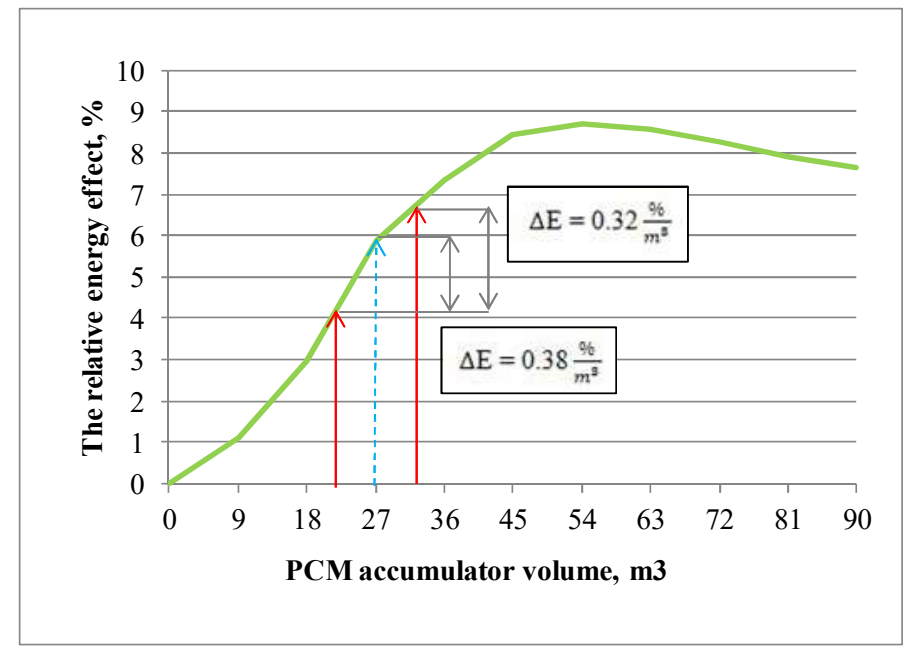

Fig. 6. The effect of energy - economical solutions.

An important criterion is also the economic indicator, ie the investment return time, which consists of purchase costs of phase change material (PCM), costs of accumulator construction, necessary diagnostic reviews and repairs. Depending on the PCM 
accumulator volume used, the payback time of the investment changes. In the case of using a PCM accumulator with a volume determined in step 2, ie a volume in the range of 22-27 $\mathrm{m}^{3}$, the investment will be returned after 11 years for a volume of $22 \mathrm{~m}^{3}$ and after 15 years for a volume of $27 \mathrm{~m}^{3}$, as shown in Figure 7.

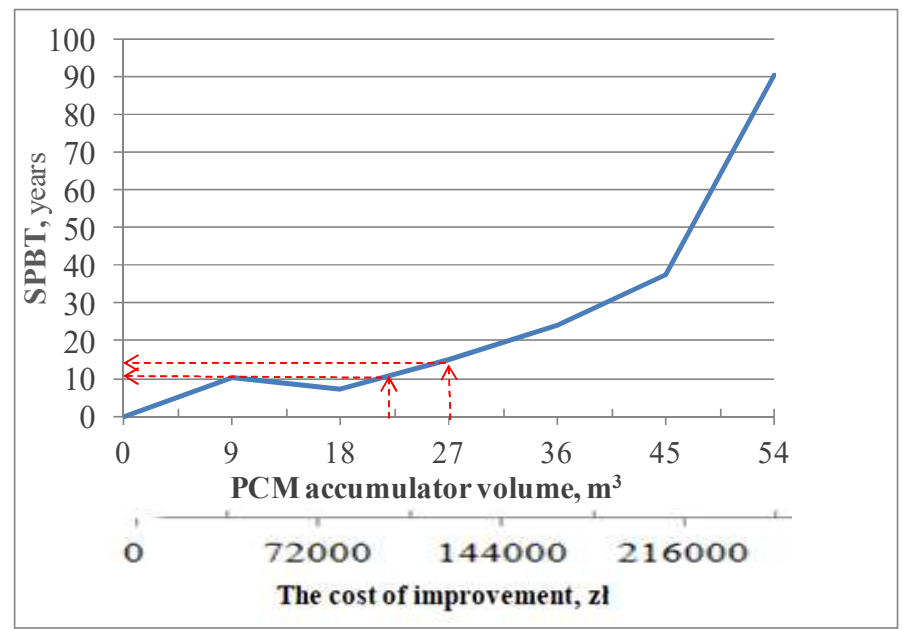

Fig. 7. The economic effect of the applied solution.

\section{Conclusions}

Heat storage in the heat distribution network on the return side of low parameters has a significant impact on the return temperature of the district heating system. The main element that has an impact on reducing the temperature difference resulting from the use of the regulatory table and differences in the perception of heat by users is the capacity of the heat accumulators.

The use of PCM accumulator on substation allowed to limit the temperature discrepancy of the return of the heating network with a maximum of $\Delta \mathrm{T}_{\max }=30 \mathrm{~K}$ to $\Delta \mathrm{T}_{\max }=10 \mathrm{~K}$, which constituted an improvement of the network regulation by $67 \%$.

Thanks to the use of distributed PCM accumulators, approximately $6.7 \%$ energy saving, maintaining a relatively constant return temperature of the heating network, and achieving an economic effect in the form of a return on investment, which is 13 years on average, is possible.

The material has been prepared in terms of Czestochowa University of Technology statutory research BS/PB-407-302/11 "Energy-efficient and environmentally sustainable supply systems of buildings in heat, coldness and electricity" and BS/MN-407-301/16 "Heat storage in district heating system".

\section{References}

1. J. Xu, R.Z. Wang, Y. Li, Sol. Ener., 103, p: 6010-638 (2014)

2. K. Nogaj, Pr. Nauk. Uni. Ekon. we Wroc., 461, p: 157-169 (2016)

3. M. Turski, R. Sekret, E3S Web of Conf., 00180, 22, p: 1-6 (2017)

4. M. Johnson, J. Vogel, M. Hempel, A. Dengelb, M. Seitz, B. Hachmannc, Ene. Proc., 73, p: 281-288 (2015)

5. J. Milewski, M. Wolowicz, W. Bujalski, Jour. of Pow. Tech., 94 (3), p: 153-164 (2014) 
6. K. Nogaj, Bad. i Roz. Młod. Nauk. w Pol. - Ener. (red.) Leśny J., Nyćkowiak J, Rozdzial w monografii, p: 28-36 (2016)

7. B. Regulski, P. Ziembicki, J. Bemasiński, A. Węglarz, Ryn. Ener., sierpień (2014)

8. I.B. Hassine, U. Eicker, App. Ther. Engine., 50, p: 1437-1446 (2013)

9. J. Piechocki, Podl. Fund. Rozw. Reg., 118 (2006)

10. R. Śniezyk, Energet., 8, p: 1-15 (2011)

11. A. Jurkiewicz, COW 43/5, p: 183-186 (2012)

12. D. Chwieduk, Sol. Ener., 19, No. 3, p: 473-478 (2010)

13. K. Nogaj, M. Turski, R. Sekret, COW, T. 48, nr 2, p: 47-52 (2017)

14. M. Turski, R. Sekret, Ryn. Ciepła, Praca zbiorowa pod redakcją Henryka Kapronia, p: 23-38 (2015)

15. P. Feliński, R. Sekret, Ener. And Build., 152, p: 558-567 (2017)

16. K. Nogaj, M. Turski, R. Sekret, E3S Web of Conf., 00124, 22, p: 1-7 (2017)

17. R. Sekret, Wyd. Poli. Częst., seria Monografie (2012)

18. M. Turski, R. Sekret, Chem. and Proc. Engine., 37 (2), p: 293-304 (2016)

19. P. Feliński, R. Sekret, Ener., 114, p: 1063-1072 (2016) 